\title{
Influence of FIMA burnup on actinides concentrations in PWR reactors
}

\author{
Mikołaj Oettingen ${ }^{1}$ and Katarzyna Skolik ${ }^{1}$ \\ ${ }^{1}$ AGH University of Science and Technology, al. Mickiewicza 30, 30-059 Krakow, Poland
}

\begin{abstract}
In the paper we present the study on the dependence of actinides concentrations in the spent nuclear fuel on FIMA burnup. The concentrations of uranium, plutonium, americium and curium isotopes obtained in numerical simulation are compared with the result of the post irradiation assay of two spent fuel samples. The samples were cut from the fuel rod irradiated during two reactor cycles in the Japanese Ohi-2 Pressurized Water Reactor. The performed comparative analysis assesses the reliability of the developed numerical set-up, especially in terms of the system normalization to the measured FIMA burnup. The numerical simulations were preformed using the burnup and radiation transport mode of the Monte Carlo Continuous Energy Burnup Code - MCB, developed at the Department of Nuclear Energy, Faculty of Energy and Fuels of AGH University of Science and Technology.
\end{abstract}

\section{Introduction}

The aim of the study is a comparative analysis between measured and calculated actinide concentration in function of FIMA burnup to assess its influence on the $C / E$ ratios (calculated-to-experimental), which define agreement between experimental measurements and numerical calculations. The change in the nuclear fuel composition caused by the series of nuclear transmutations and radioactive decays is called fuel burnup. The burnup in FIMA units (Fission per Initial Metal Atom) describes the net change of heavy metal in the specified piece of a nuclear fuel at the specified irradiation time. The measured burnup of the irradiated nuclear fuel is the crucial parameter for the numerical reconstruction of the irradiation experiment e.g. in the terms of validation of numerical models, libraries and codes. In this way, using measured experimental data and the data obtained in the numerical simulation the relationship between the real world and the computational model could be defined. However, this kind of study must be based on some reference measurements obtained in dedicated experiments.

The Ohi-2 irradiation experiment was chosen for the study because the reported experiment specification was sufficient for the reliable numerical reconstruction using the $\mathrm{MCB}$ code. The reference data applied in the analysis are mainly based on the two scientific publications: the paper of T. Adachi et al. [1] and the paper of K. Suyama et al. [2]. The papers include the comprehensive knowledge about performed post irradiation examination of the spent fuel samples, irradiation history and fuel assembly design. Thus, the papers provide the reliable and robust source of information for numerical reconstruction.

\section{PWR reactors}

Pressurized Water Reactor (PWR) is the most popular and best known type of nuclear reactor in the world. Currently (May 2016) there are about 285 PWRs in commercial operation which represent approximately $65 \%$ of the entire nuclear fleet - see Fig. 1 [3]. They use common and cheap light water as a coolant and a moderator, employ uranium fuel with enrichment no bigger than $5 \%$ and consist of two separated circuits what helps to minimize potential radioactive releases to the environment. The pressure of about $15 \mathrm{MPa}$ in primary circuit allows to maintain liquid state of the water that reaches temperature above $300^{\circ} \mathrm{C}$.

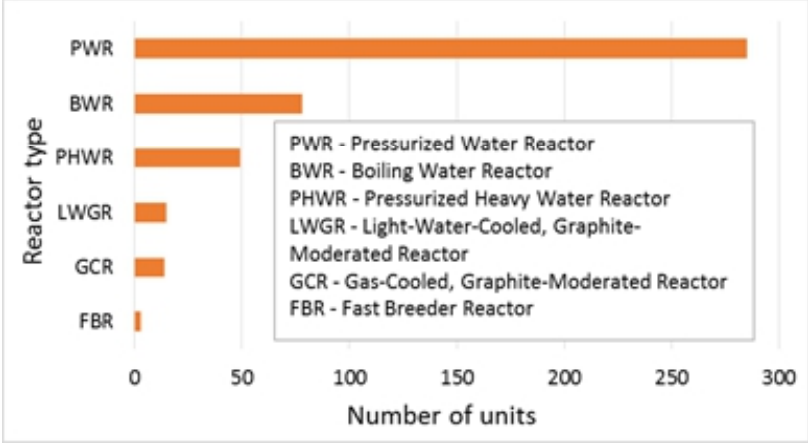

Figure 1. Nuclear reactors by type [3].

Since the first full-scale commercial PWR was connected to the grid in 1957 (Shippingport Nuclear Power Plant (NPP), USA), the design was constantly being improved in order to achieve bigger power output, longer lifetime of the reactor and better safety features. PWRs that are in operation nowadays belong mostly to generation II of nuclear reactors [4]. Specific models originate from the USA (Westinghouse, Babcock\&Wilcox and General Electric designs), France 
(Framatome /now Areva/), Russia (VVER reactors by OKD Gidropress), China and South Korea. Nearly $50 \%$ operating NPPs in the world are based on US Westinghouse technologies. The electrical power output from one reactor is $1000 \mathrm{MW}_{\mathrm{e}}$ on average and predicted lifetime of a plant is approximately 60 years. Evolution of PWR design still continues and now generation II+, III and III+ reactors are developed and constructed, mostly in the countries mentioned above [5].

The newest PWR designs in the USA are AP1000, APWR and APWR+. Westinghouse AP1000 is the first generation III+ reactor with the approval from U.S. Nuclear Regulatory Commission. The first unit will start its operation in 2017 in China and four more are now under construction in the USA. APWR and APWR+ are developed by Mitsubishi Heavy Industry. The second one is planned to have increased power output (up to $1700 \mathrm{MW}_{\mathrm{e}}$ ) and full Mixed-Oxide Fuel (MOX) fuel ability.

European Pressurized/Evolutionary Power Reactor (EPR), with the output electrical power of $1650 \mathrm{MW}_{\mathrm{e}}$ was developed mainly by Framatome (Areva) in France and Siemens in Germany. Four units are under construction, one each in France and Finland and two in China. However all of them suffer from long-term delays because of complexity and expensiveness of the project.

Chinese models, CPR1000 (gen. II+) and ACPR1000 (gen. III) are the first reactors created in this country intended for the international market. By now they are only operating or being constructed in China - about 25 in total.

The latest version of the Russian VVER is called VVER-1200, offered for domestic and export use. A lot of reactors of this type are planned in Bangladesh, China, Hungary, Indonesia and Vietnam and are being constructed in Russia and Finland [5].

A common features of all new PWR designs are increased power, extended lifetime of a plant and lower risk of failure. The bigger output power is intended to improve economic performance according to the effect of scale (the profits gained during operation time exceeds the additional investments during construction). The increased level of safety is achieved by introduction of passive safety systems [6], installation of redundant devices and systems and, in many cases, presence of so-called core catcher.

\section{Irradiation}

The actinide concentrations were obtained in the destructive assay of two uranium fuel samples irradiated in the 17x17 fuel assembly at the Japanese Ohi2 PWR of the Kansai Electric Power Company Inc. The fuel samples indexed as 89G08 and 89G010 were cut from the $\mathrm{UO}_{2}\left(3.2\right.$ wt. $\left.\%{ }^{235} \mathrm{U}\right)$ fuel pin named $\mathrm{F} 4$ - see Fig 2 . The considered leading $17 \times 17$ fuel sub-assembly was irradiated during two reactor cycles from Jul. 1984 to Feb. 1987. The first cycle lasted 410 full power days, while the second one 427 full power days. The operational outage between cycles lasted 104 days. The leading fuel assembly was discharged at the average burnup of $31.5 \mathrm{GWd} / \mathrm{t}$.

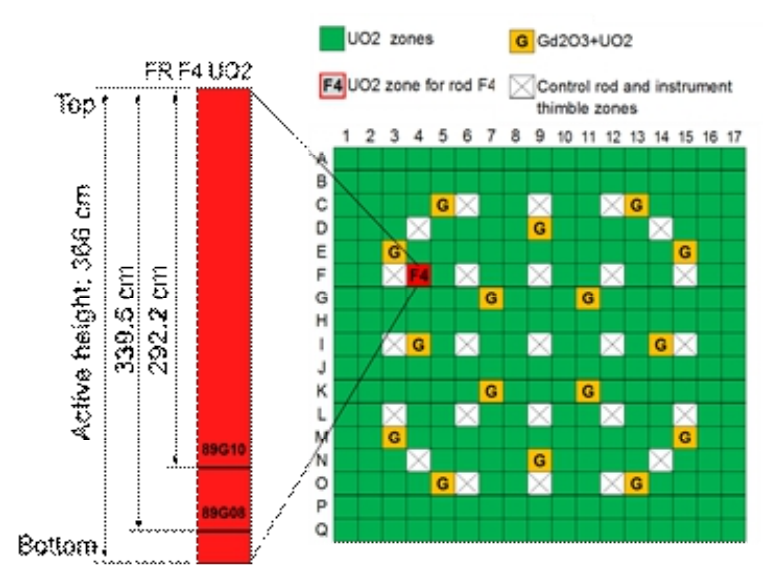

Figure 2. Location of the investigated fuel samples in the fuel rod and assembly.

\section{Experimental}

The post irradiation examination of the spent fuel samples was conducted at the Japan Atomic Energy Research Institute in 1987, just after removal of the fuel assembly from the reactor core. The non-destructive testing included: gamma scanning of fuel rods, mass spectrometry of the gaseous fission products, visual examination, crude analysis, profilometry, fuel stack elongation measurement and X-ray radiography. Fig. 3 shows the flowchart of the destructive assay, which follows to the final measurements of the actinide concentrations and burnups. The measured actinide concentrations are necessary to quantify sample burnup, which is the crucial parameter for the burnup calculations using the MCB code. The burnups in FIMA units were calculated using measured concentrations of ${ }^{148} \mathrm{Nd}, \mathrm{U}$, $\mathrm{Np}, \mathrm{Pu}, \mathrm{Am}, \mathrm{Cm}$ and effective fission yields using ${ }^{148} \mathrm{Nd}$ method.



Figure 3. Flowchart of destructive assay.

\section{Numerical}

Usually, in the neutron transport and burnup calculations the numerical reconstruction focuses only on the most important components of the engineering geometry influencing neutronic parameters, like neutron fluxes 
and spectra. Therefore, the engineering geometry does not need to be exactly transferred to the computational geometry of the numerical model.

Thus, the fuel in fuel rods was not divided into particular fuel pellets. However, it was divided into six radial and fourteen axial burnup zones. Hence, the whole fuel in the assembly was represented by the 84 independent zones - two of them correspond to the investigated fuel samples. This kind of division was purposefully chosen to reflect the physics of the fuel sample with high accuracy.

All layers above the fuel column constitute the top reflector while all layers below fuel column constitute the bottom reflector. The modelling of the reactor core at the level of the fuel assembly demands introduction of the reflective boundary conditions on the vertical edges of the numerical model, which was done in all presented calculations.

The critical or subcritical fissile system reconstructed using the MCB code has to be normalized to the total thermal power released during operation time [7, 8]. The simulations of the $17 \times 17$ fuel assembly were normalized to the total thermal power using the $\mathrm{Q}_{\text {fiss }}$ values implemented in the JEFF3.1 cross section libraries [9]. Providing the average assembly discharge burnup $B$, $31.5 \mathrm{GWd} / \mathrm{t}$, duration of the reactor cycles $t, 837$ days and initial content of heavy metal in the fuel $m_{\text {init }}, 451.76 \mathrm{~kg}$, the Eq. (1) can be used to calculate absolute thermal power $P$, which equals $16.94 \mathrm{MW}_{\text {th. }}$. The initial mass of heavy metal was derived using the reference fuel assembly geometry and fuel composition. The average system power was applied to perform initial MCB simulations.

$$
B=\frac{P \cdot t}{m_{\text {init }}}
$$

The final mass of heavy metal in the investigated fuel zones $-m_{\text {final }}$ was obtained in the initial simulations. Then, FIMA burnup in fuel zones representing fuel samples could be calculated using Eq. (2). To adjust the initial FIMA from simulation to the reference FIMA from experimental measurements the initial calculations were rerun applying the same system thermal power (16.94 $\mathrm{MW}_{\text {th }}$ ) but changing irradiation time. This procedure allows the direct adjustment of the calculated FIMA to the reference FIMA.

$$
\text { FIMA }=\left(1-\frac{m_{\text {final }}}{m_{\text {init }}}\right) \cdot 100 \quad[\%]
$$

In the next step the sensitivity analysis of the actinide concentration to the changes in FIMA burnup was performed. For this reason the irradiation time was modified to increases or decrees FIMA burnup up to $2 \%$. This procedure can be applied because the FIMA behaves in linear manner, which helps to predict targeted FIMA after assumed irradiation time.

The calculations for all time steps were performed in the kcode mode with the initial neutron multiplication factor set to 1.0. The number of inactive generations was set to 40 and the number of active generations to 100 . In each generation 50000 neutrons were simulated, which gives $7 \times 10^{6}$ particle histories.

\subsection{Sample $89 \mathrm{G} 08$}

Table 1 presents the $C / E$ ratios for the lower sample 89G08 with the reference measured FIMA burnup of 3.129. The green fields show the acceptable agreement in the range of $5 \%$, the orange fields medium agreement in the range of $10 \%$ while the read field poor agreement above $10 \%$, comparing with the measured concentrations. Among isotopes of uranium and plutonium the best agreement was achieved either for reference burnup or for burnup increased by $1 \%$. The results for isotopes of americium and curium show unpredictable behaviour comparing to the experimental measurement. However, general trends in concentration changes are proper i.e. $C / E$ ratios of all not-fissile isotopes increase with FIMA burnup, which means their accumulation in the fuel assembly.

Table 1. Calculated-to-Experimental ratios for sample 89G08.

\begin{tabular}{|l|c|c|c|c|c|}
\hline \multirow{2}{*}{ C/E } & \multicolumn{5}{|c|}{ FIMA } \\
\cline { 2 - 6 } & $-2 \%$ & $-1 \%$ & $0 \%$ & $1 \%$ & $2 \%$ \\
\hline U232 & 0.78 & 0.80 & 0.82 & 0.85 & 0.87 \\
\hline U234 & 1.02 & 1.01 & 1.00 & 1.00 & 0.99 \\
\hline U235 & 1.08 & 1.07 & 1.05 & 1.03 & 1.02 \\
\hline U236 & 0.98 & 0.99 & 0.99 & 1.00 & 1.00 \\
\hline U238 & 1.00 & 1.00 & 1.00 & 1.00 & 1.00 \\
\hline Np237 & 1.00 & 1.02 & 1.03 & 1.04 & 1.06 \\
\hline Pu236 & 1.25 & 1.28 & 1.32 & 1.35 & 1.38 \\
\hline Pu238 & 0.87 & 0.90 & 0.92 & 0.94 & 0.97 \\
\hline Pu239+Np239 & 1.01 & 1.01 & 1.01 & 1.01 & 1.01 \\
\hline Pu240 & 0.99 & 1.00 & 1.01 & 1.01 & 1.02 \\
\hline Pu241 & 0.97 & 0.98 & 0.99 & 1.01 & 1.02 \\
\hline Pu242 & 0.94 & 0.96 & 0.99 & 1.01 & 1.04 \\
\hline Am241 & 0.86 & 0.87 & 0.89 & 0.89 & 0.91 \\
\hline Am242m & 0.97 & 0.99 & 1.01 & 1.02 & 1.04 \\
\hline Am243 & 0.99 & 1.03 & 1.06 & 1.10 & 1.14 \\
\hline Cm242 & 0.76 & 0.78 & 0.80 & 0.83 & 0.85 \\
\hline Cm243 & 0.63 & 0.65 & 0.67 & 0.69 & 0.72 \\
\hline Cm244 & 0.93 & 0.98 & 1.02 & 1.08 & 1.13 \\
\hline Cm245 & 1.00 & 1.06 & 1.13 & 1.21 & 1.28 \\
\hline Cm246 & 0.79 & 0.85 & 0.91 & 0.99 & 1.07 \\
\hline Cm247 & 0.65 & 0.71 & 0.76 & 0.84 & 0.93 \\
\hline
\end{tabular}

\subsection{Sample 89G10}

Table 2 presents the $C / E$ ratios for the upper sample 89 G10 with the reference measured FIMA burnup of 3.980. The burnup for this samples is higher because of increases of absolute neutron flux value towards centre of fuel assembly. The $C / E$ ratios for almost all actinides show much better agreement with experimental measurements comparing to the sample 89G08. The reason for this could be attributed to the better reconstruction of irradiation conditions towards centre of fuel assembly because the spectral effects related to the influence of bottom reflector partly disappear. The best results were achieved for the reference FIMA or FIMA increased by $1 \%$ similarly to sample $89 \mathrm{G} 08$. However, this sample shows large improvements for ${ }^{232} \mathrm{U},{ }^{241} \mathrm{Am}$, and curium isotopes except ${ }^{246} \mathrm{Cm}$. 
Table 2. Calculated-to-Experimental ratios for sample 89G08.

\begin{tabular}{|l|c|c|c|c|c|}
\hline \multirow{2}{*}{ C/E } & \multicolumn{5}{|c|}{ FIMA } \\
\cline { 2 - 6 } & $-2 \%$ & $-1 \%$ & $0 \%$ & $1 \%$ & $2 \%$ \\
\hline U232 & 0.98 & 1.01 & 1.04 & 1.06 & 1.09 \\
\hline U234 & 1.01 & 1.00 & 0.99 & 0.98 & 0.98 \\
\hline U235 & 1.09 & 1.07 & 1.05 & 1.03 & 1.01 \\
\hline U236 & 0.98 & 0.99 & 0.99 & 0.99 & 1.00 \\
\hline U238 & 1.00 & 1.00 & 1.00 & 1.00 & 1.00 \\
\hline Np237 & 1.05 & 1.07 & 1.08 & 1.09 & 1.10 \\
\hline Pu236 & 1.15 & 1.17 & 1.20 & 1.23 & 1.26 \\
\hline Pu238 & 0.90 & 0.92 & 0.95 & 0.97 & 0.99 \\
\hline Pu239+Np239 & 1.00 & 1.00 & 1.00 & 1.00 & 1.00 \\
\hline Pu240 & 0.96 & 0.97 & 0.98 & 0.99 & 1.00 \\
\hline Pu241 & 0.98 & 0.98 & 0.99 & 0.99 & 1.00 \\
\hline Pu242 & 0.93 & 0.95 & 0.97 & 0.99 & 1.01 \\
\hline Am241 & 0.90 & 0.91 & 0.92 & 0.92 & 0.93 \\
\hline Am242m & 1.19 & 1.20 & 1.22 & 1.22 & 1.23 \\
\hline Am243 & 0.96 & 0.99 & 1.02 & 1.05 & 1.08 \\
\hline Cm242 & 0.91 & 0.92 & 0.94 & 0.96 & 0.98 \\
\hline Cm243 & 0.85 & 0.87 & 0.89 & 0.91 & 0.93 \\
\hline Cm244 & 0.92 & 0.95 & 1.00 & 1.04 & 1.08 \\
\hline Cm245 & 0.95 & 1.00 & 1.04 & 1.12 & 1.19 \\
\hline Cm246 & 0.77 & 0.82 & 0.88 & 0.94 & 1.01 \\
\hline Cm247 & 0.88 & 0.95 & 1.03 & 1.12 & 1.21 \\
\hline
\end{tabular}

\section{Conclusions}

The results of the study provide a technical basis for the sensitivity study on actinide concentration in function of FIMA burnup. The results show that MCB code reflects the physics of 17x17 fuel assembly with high accuracy. The general performances associated burnup calculations show good consistence with theoretical predictions and the final actinide concentrations obtained in burnup calculations present rather good agreement with experimental measurements.

However, some inconsistence in concentrations of ${ }^{232} \mathrm{U},{ }^{239} \mathrm{Pu},{ }^{241} \mathrm{Am},{ }^{242 \mathrm{~m}} \mathrm{Am}$ and $\mathrm{Cm}$ isotopes were observed. The large deviations in $C / E$ ratios may either indicate to some errors in experimental measurement or in the numerical set-up. The applied sensitivity analysis via change in FIMA burnup can lead to improvements for some particular isotopes but it deviates the final results for other isotopes. The improvement in $C / E$ ratios could be achieved rather by increasing than decreasing FIMA burnup. In addition, it is worth mentioning, that the better coherency was achieved for isotopes of uranium and plutonium because the transmission chains following formation of these isotopes are quite simple unlike for americium and curium isotopes.

\section{Acknowledgements}

The research was supported in part by PL Grid Infrastructure available at Academic Computer Centre CYFRONET AGH. In addition, partial financial support of this study through the funds of the Polish Ministry of Science and Higher Education is kindly acknowledged.

\section{References}

1. T. Adachi, Y. Nakahara, N. Kohno, K. Gunji, T. Suzuki, T. Sonobe, M. Onuki, K. Kato, E. Tachikawa, S. Inoue, M. Takayasu, M. Yoshikuni, S. Kobayashi, Z.
Teruya, T. Kawamoto, M. Kawamura, J. Nucl. Sci. Technol. 31, 10 (1994)

2. K. Suyama, M. Murazaki, K. Ohkubo, Y. Nakaharac, G. Uchiyama, Ann. Nucl. Energy 38, 930-941 (2011)

3. The Power Reactor Information System, International Atomic Energy Agency, [online], [access: 13-05-2016], Available in World Wide Web: www.iaea.org/pris/

4. S. M. Goldberg, R. Rosner, Nuclear Reactors: Generation to Generation. American Academy of Arts \& Sciences (2011)

5. World Nuclear Association, [online], [access: 13-052016], Available in World Wide Web: www.worldnuclear.org

6. S. Er-bing, C. Fang, C. Wang, G. Xia, C. Zhao, Ann. Nucl. Energy 85, (2015)

7. J. Cetnar, G. Domańska, P. Gajda, J. Janczyszyn, Nukleonika 59, (2014)

8. J. Cetnar, General Solution of Bateman Equations for Nuclear Transmutations, Ann. Nucl. Energy 33, (2006)

9. G. Kępisty, J. Cetnar, P. Stanisz, Ann. Nucl. Energy 94, (2016) 